\title{
Oral Impacts Experienced by Orthodontic Patients Undergoing Fixed or Removable Appliances Therapy in Saudi Arabia: A Cross-Sectional Study
}

\author{
Mohammad Abdul Baseer (D) \\ Nawaf Abdulaziz Almayah ${ }^{2}$ \\ Khalid Mirae Alqahtani ${ }^{2}$ \\ Marwan Ibrahim Alshaye ${ }^{2}$ \\ Meshari Mohammed Aldhahri ${ }^{2}$ \\ 'Department of Preventive Dentistry, \\ College of Dentistry, Riyadh Elm \\ University, Riyadh, Saudi Arabia; ${ }^{2}$ College \\ of Dentistry, Riyadh Elm University, \\ Riyadh, Saudi Arabia
}

\begin{abstract}
Purpose: The objective of this study is to compare the orthodontic patient's experiences with removable and fixed orthodontic appliances on daily activities, food consumption, and oral symptoms in Riyadh city, Saudi Arabia.

Methods: This was a cross-sectional observational study carried out among orthodontic patients. A total of 150 adult patients, including 118 in the fixed orthodontic appliance group and 32 in the removable (Invisalign) orthodontic group, who met the inclusion criteria completed a validated and self-administered questionnaire. In addition, the study participants reported their experience in terms of daily routine, food consumption, and oral symptoms one week after appliance activation. Data were analyzed using the chi-square test and Fisher's exact tests for the categorical variables. In addition, Mann-Whitney U, KruskalWallis, and Spearman's tests were also applied to the data.

Results: The fixed orthodontic patients compared to the removable orthodontic cases showed significantly higher difficulty in sleeping $(1.28 \pm 1.10$ vs $0.94 \pm 0.88, \mathrm{p}=0.024)$, sores on the tongue $(0.97 \pm 1.00$ vs $0.56 \pm 0.76, \mathrm{p}=0.042)$ and cheeks $(1.20 \pm 1.11$ vs $0.72 \pm 0.81, \mathrm{p}=0.027)$, and the presence of food debris under the appliance $(1.53 \pm 1.16$ vs. $1.00 \pm 0.95, \mathrm{p}=0.021)$. Moreover, the oral health impact score showed a significant positive correlation with the duration of the orthodontic treatment $(\mathrm{r}=0.339, \mathrm{p}<0.001)$ and pain intensity $(\mathrm{r}=0.309, \mathrm{p}<0.001)$.
\end{abstract}

Conclusion: The fixed orthodontic treatment compared to removable orthodontic treatment resulted in more severe pain, sleeping difficulty, sores on the tongue and cheeks, and food impaction after one week of appliance activation.

Keywords: removable appliance, orthodontic treatment, fixed appliance, Invisalign, oral impacts, oral health-related quality of life, OHRQoL

\section{Introduction}

Malocclusion is often considered to negatively influence an individual's physical, social, and psychological well-being and self-esteem. ${ }^{1-3}$ Therefore, patients pursue orthodontic treatment to enhance their appearance, dental function, psychological well-being, and quality of life. Esthetic improvement is the primary motive for adult patients seeking orthodontic treatment. ${ }^{4,5}$

The orthodontic need assessments in Saudi Arabia have revealed that crowding was the most common malocclusion trait, followed by increased overjet and spacing. ${ }^{6}$ It has been reported that the $40-62.4 \%$ of the population needs orthodontic treatment. ${ }^{7,8}$ Because of greater awareness of the benefits of orthodontic treatment, the number of people seeking orthodontic treatment has increased during the previous two decades. ${ }^{8}$ The rising demand for orthodontic treatment, along with the government's limited
Correspor

Department of Preventive Dentistry, College of Dentistry, Riyadh Elm University, Post Box No 8489I, Riyadh, I 168I, Saudi Arabia

Email ma_baseer@riyadh.edu.sa 
ability to offer orthodontic services, has prepared the way to establish private orthodontic clinics in Saudi Arabia. ${ }^{9}$

Orthodontic patients may require either removable appliance or fixed appliance therapy based on the diagnosis and severity of the condition. The components of fixed orthodontic appliances such as brackets may have an unsightly look, functional restrictions, discomfort, and pain during therapy, affecting the patients' oral healthrelated quality of life. ${ }^{10-12}$ Past studies have outlined the differences between removable and fixed orthodontic treatment appliances concerning esthetics, cost, technical and dental health factors, and patients' experiences. ${ }^{13}$ Pain and discomfort levels of the patients undergoing removable and fixed dental appliance therapy varied across the groups. ${ }^{14}$ Moreover, some studies reported more eating disturbance among patients treated with conventional fixed orthodontic appliances than removable appliance therapy. ${ }^{15}$

Many tools, including the Psychosocial Impact of Dental Aesthetics Questionnaire (PIDAQ), ${ }^{16}$ the Child Oral Impact on Daily Performance, ${ }^{17}$ and the Child Oral Health Impact Profile, ${ }^{18}$ were previously used to examine OHRQoL in connection to orthodontic appliance treatment. The short-term oral Impact scale utilized by Alajmi et al is one of the indicators to measure the oral impacts of orthodontic treatments that affect an individual's daily activities. It consists of fourteen items that assess the effects of orthodontic appliances on daily activities, disturbances in eating, and oral symptoms. ${ }^{19}$ According to Zamora-Martinez et al, the quality of life of orthodontic patients decreased significantly throughout therapy compared to their pre-treatment status but increased considerably at the end of treatment. ${ }^{20}$

Orthodontic appliances are expected to negatively impact OHRQoL because of the position and design of removable and fixed appliances. However, previous research found inconsistent results when evaluating the impact of removable and fixed orthodontic treatment techniques on oral health-related quality of life. ${ }^{15,21}$ These contradictory results may be related to the small sample size, which calls for larger-sample-size investigations. Furthermore, it is unclear if patients who receive removable appliance therapy report less oral health impacts than the fixed appliance orthodontic treatment. ${ }^{22}$

Comparison of oral health impacts of removable and fixed orthodontic treatment is still a concern and needs further evidence to choose the type of orthodontic appliance therapy in clinical practice. Moreover, in Saudi
Arabia, limited studies documented the impact of removable appliances on OHRQoL. ${ }^{23,24}$ Hence the present study compared the patients' experience with removable and fixed orthodontic appliances in daily activities, food consumption, and oral symptoms in Riyadh city, Saudi Arabia. This study hypothesized that limitations of daily activities, food consumption, and oral symptoms differed between patients receiving removable and fixed appliances orthodontic treatment.

\section{Materials and Methods}

A cross-sectional study was carried out among a sample of active orthodontic patients in Riyadh city, Saudi Arabia. The study was conducted from April to July 2021. The ethical approval for the study was obtained from the research center of Riyadh Elm University (FIRP/2021/89/ 429/420). Before participating in the study, each patient was given oral and written information and signed a written consent form. This study was conducted in accordance with the Declaration of Helsinki.

All patients were recruited systematically based on the following inclusion criteria: 18-35 years of age, simple to moderate orthodontic treatment need, absence of missing teeth, and agreed to answer the questionnaire. In contrast, orthodontic patients with Class III malocclusion, skeletal abnormalities, cleft lip or palate, craniofacial disturbances, and systemic diseases were excluded.

\section{Study Sample}

Based on the convenience sampling methodology, few governments and private dental clinics providing orthodontic treatment in Riyadh city were selected for the study purpose. Furthermore, due to the retrospective character of the study, patients were divided into two groups based on treatment modality (fixed or removable appliance therapy) employed but not on the treatment stage or type of teeth movement. Removable appliances included Invisalign Clear aligner treatment modality.

\section{Sample Size Calculation}

A sample of $(\mathrm{N}=150)$ orthodontic patients undergoing fixed and removable treatment was calculated by considering alpha error probability of 0.05 , power 0.80 , allocation ratio of 0.271 , and effect size of 0.58 required for the Wilcoxon-Mann-Whitney test. 


\section{Study Instrument}

The demographic part of the previously used instrument by Alajmi et $\mathrm{al}^{15}$ was changed and utilized in this investigation. Moreover, medication intake to relieve the pain was also assessed by the patients. The questionnaire consisted of three sections; the first section contained information on demographic variables (age, gender, education, income, and residence), second section dealt with orthodontic treatment-related information and associated pain (orthodontic treatment type, duration of treatment, type of practice, pain rating and intake of medication). The third part included items that assessed limitations to the daily routine, disturbances to eating, and presence of oral symptoms measured on a five-point Likert scale; $1=$ no instances (never affected), 2 = few instances (less than once a month), $3=$ some instances (once or twice a month), $4=$ several instances (once or twice a week), 5=numerous instances) (3-4 times a week/nearly every day). In addition, the pain due to orthodontic treatment was assessed on a visual analog scale of $0-10$. The pain scale is further categorized into mild (1-3), moderate (47 ), and severe (8-10). Responses to the third part questionnaire were dichotomized by considering no instances $=0$ and all other instances $=1$. Finally, the scores of all the 14 items were added to obtain the overall impact of fixed and removable orthodontic treatment. An impact scale ranged between 0-14. A high oral impact score indicates poor health-related quality of life.

\section{Questionnaire Administration}

After forward and reverse translation, the study questionnaire was created in both English and local Arabic languages with the aid of a bilingual specialist. For data collection, the electronic version of the questionnaire was created using Google forms. In addition, two trained investigators visited government and private orthodontic clinics to gather information. Patients attending orthodontic clinics for appliance activation were approached, and treatment information was documented. Those who met the requirements and consented to participate in the study were recalled one week after the appliance was activated to complete a Google form using an Apple iPad to selfreport the questionnaire items. The investigator clarified any doubts during questionnaire administration. The questionnaire's face validity was determined by soliciting expert comments (dental public health practitioner), and the questionnaire was found to be reliable (Cronbach's alpha $=0.88$ ).

\section{Statistical Analysis}

Data was gathered and analyzed using Statistical Package for Social Sciences (IBM-SPSS version 25, Armonk, NY: USA). Descriptive statistics of frequency distribution and percentages were calculated for the categorical variables, and the Chi-square test and Fisher's exact tests were used to analyze variables. Similarly, mean, standard deviation values were calculated for the continuous variables of age, duration of the orthodontic treatment, and pain rating. Shapiro-Wilk's test of normality indicated the non-normal distribution of the data $(p<0.05)$. Hence the mean rank of overall impact was compared between fixed and removable orthodontic treatments using non-parametric tests of Mann-Whitney U and Kruskal-Wallis tests. Finally, Spearman's test was applied to assess the correlation of type of orthodontic treatment on pain and overall impact score. A value of $p<0.05$ was considered statistically significant for all the statistical tests.

\section{Results}

A total of 150 orthodontic patients undergoing fixed $(n=118)$ and removable $(n=32)$ orthodontic treatment agreed to participate in the study. Most of the orthodontic patients received treatment in private dental clinics rather than the government. Fixed orthodontic patients had a higher mean age (24.85 \pm 8.13 years) and sought a more extended period of treatment (11.51 \pm 10.19 months) than removable orthodontic patients. In addition, significantly higher fixed orthodontic treatment patients than the removable patients $(4.87 \pm 2.28$ vs $4.03 \pm 1.99, \mathrm{p}=0.028)$ complained of oral pain. Accordingly, pain medications were used by a higher proportion of fixed orthodontic patients, $72(61.0 \%)$, than removable $14(43.8 \%)$ orthodontic cases. Demographic characteristics and orthodontic treatment variables are shown in (Table 1).

In a few instances, orthodontic patients reported difficulty in speaking 51 (34.0\%), enjoying meals 59 (39.3\%), opening their mouth 55 (36.7\%), and food debris underneath the appliances 47 (31.3\%). Similarly, 49 (32.7\%) reported being unable to eat meals in some instances. Furthermore, 52 (34.7\%) and 57 (38.0\%) subjects experienced sores on their cheeks and lips. The frequency distribution of the responses is shown in (Figure 1). The highest mean item impact score was observed with difficulty in daily activities $1.59 \pm 1.12$ followed by the disturbance in work and study $1.58 \pm 1.11$, presence of food debris under the appliance $1.41 \pm 1.14$, and the least score 
Table I Demographic Characteristics and Type of Orthodontic Treatment

\begin{tabular}{|c|c|c|c|c|c|c|}
\hline \multicolumn{2}{|l|}{ Variables } & \multicolumn{2}{|c|}{ Fixed } & \multicolumn{2}{|c|}{ Removable } & \multirow[t]{2}{*}{$\mathbf{p}$} \\
\hline & & $\mathbf{n}$ & $\%$ & $\mathbf{n}$ & $\%$ & \\
\hline \multirow[t]{3}{*}{ Gender } & Female & 99 & 83.9 & 29 & 90.6 & \multirow[t]{3}{*}{$0.340^{\S}$} \\
\hline & Male & 19 & 16.1 & 3 & 9.4 & \\
\hline & Total & 118 & 100.0 & 32 & 100.0 & \\
\hline \multirow[t]{3}{*}{ Education } & Intermediate/High school & 18 & 15.3 & 4 & 12.5 & \multirow[t]{3}{*}{$0.696^{\S}$} \\
\hline & College & 100 & 84.7 & 28 & 87.5 & \\
\hline & Total & 118 & 100.0 & 32 & 100.0 & \\
\hline \multirow[t]{4}{*}{ Family income (Saudi Riyals) } & $<5000$ & 21 & 17.8 & 3 & 9.4 & \multirow[t]{4}{*}{$0.316^{\S}$} \\
\hline & $5000-10,000$ & 50 & 42.4 & 12 & 37.5 & \\
\hline & $>10,000$ & 47 & 39.8 & 17 & 53.1 & \\
\hline & Total & 118 & 100.0 & 32 & 100.0 & \\
\hline \multirow[t]{3}{*}{ Type of practice } & Private & 93 & 78.8 & 24 & 75.0 & \multirow[t]{3}{*}{$0.644^{\S}$} \\
\hline & Government & 25 & 21.2 & 8 & 25.0 & \\
\hline & Total & 118 & 100.0 & 32 & 100.0 & \\
\hline \multirow[t]{3}{*}{ Pain control Medication } & Yes & 72 & 61.0 & 14 & 43.8 & \multirow[t]{3}{*}{$0.080^{\S}$} \\
\hline & No & 46 & 39.0 & 18 & 56.3 & \\
\hline & Total & 118 & 100.0 & 32 & 100.0 & \\
\hline \multicolumn{2}{|l|}{ Age of the participants (years) } & 24.85 & 8.13 & 25.03 & 8.05 & $0.747^{\pi}$ \\
\hline \multicolumn{2}{|c|}{ Duration of orthodontic treatment (Months) } & $\mathrm{II} .5 \mathrm{I}$ & 10.19 & 9.56 & 9.62 & $0.165^{\pi}$ \\
\hline \multicolumn{2}{|c|}{ Worst pain felt last week (0-10 scale) } & 4.87 & 2.28 & 4.03 & 1.99 & $0.028^{\pi}$ \\
\hline
\end{tabular}

Notes: Data are presented as $\mathrm{n}(\%)$ or mean \pm SD as appropriate. ${ }^{\S}$ Mann-Whitney U-test was used to obtain a p-value. 'Fisher's exact test used to obtain a $\mathrm{p}$-value.

was found with the item, were there any foods that you could not eat?. The mean impact score of individual items is shown in (Table 2).

The fixed orthodontic patients compared to the removable orthodontic cases showed a significantly higher effect on the sleeping difficulty $(1.28 \pm 1.10$ vs $0.94 \pm 0.88, \mathrm{p}=0.024)$, sores on the tongue $(0.97 \pm 1.00$ vs $0.56 \pm 0.76, p=0.042)$ and cheeks ( $1.20 \pm 1.11$ vs $0.72 \pm 0.81, \mathrm{p}=0.027$ ), and the presence of food debris under the appliance $(1.53 \pm 1.16$ vs. $1.00 \pm 0.95$, $\mathrm{p}=0.021$ ). However, no significant difference was observed between removable and fixed orthodontic appliances regarding other items, as shown in (Table 3).

A mean oral health impact score of $9.07 \pm 4.37$ (range $0-14$ ) was found among study participants with no significant differences across different gender, education levels, types of orthodontic treatment, and practice $(\mathrm{p}>0.05)$. However, study participants with family income $<5000$ SAR per month showed significantly lower impact scores (57.35) than those of 5000-10,000 SAR (82.75) and $>10,000$ SAR (75.28). Comparison of oral health impact score across different variables is shown in (Table 4).

Of the 118 fixed orthodontic patients, 27 (22.9\%) experienced mild, 80 (67.8\%) moderate, and 11 (9.3\%) severe pain. Likewise, of the 32 removable orthodontic cases, 11 (34.4\%) had mild, 19 (59.4\%) moderate, and 2 (6.3\%) severe pain. In addition, Spearman's tests indicated a significant positive correlation between oral health impact score and duration of the orthodontic treatment $(\mathrm{r}=0.339, \mathrm{p}<0.001)$ and oral health impact score and pain intensity $(\mathrm{r}=0.309, \mathrm{p}<0.001)$ (Table 5). 


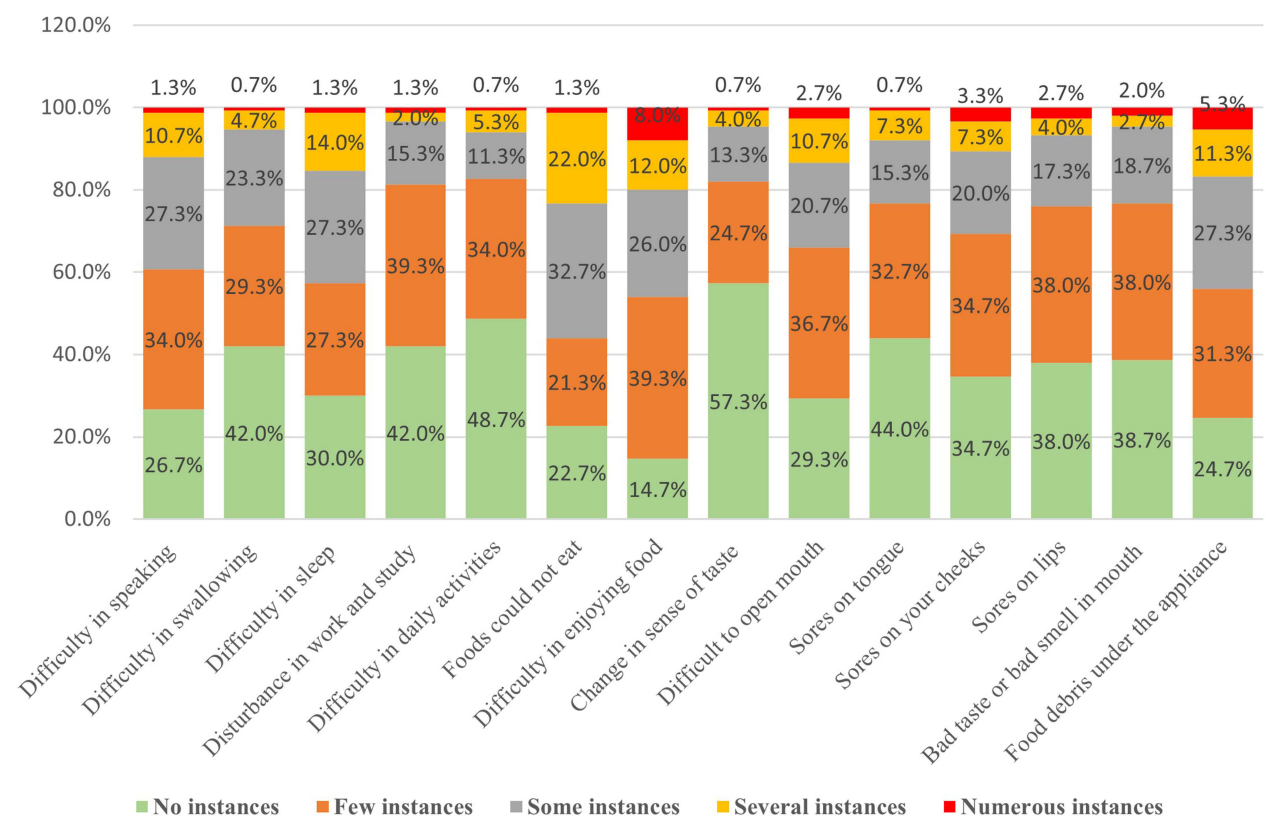

Figure I Frequency distribution of the responses to the questionnaire items.

\section{Discussion}

This study compared fixed and removable orthodontic treatment modalities utilizing a cross-sectional study design. When compared to removable orthodontic treatment, our findings indicated that the fixed orthodontic patients experienced significantly higher sleep difficulty, ulcers on the tongue and cheeks, and food impaction beneath the appliances. Moreover, the length of orthodontic treatment and pain intensity have shown a significant

Table 2 Mean and Standard Deviations Score of Each Item Response $(\mathrm{N}=\mid 50)$

\begin{tabular}{|l|l|l|l|}
\hline Items & Questions & Mean & SD \\
\hline Item I & Difficulty in speaking & 1.26 & 1.01 \\
Item 2 & Difficulty in swallowing & 0.93 & 0.95 \\
Item 3 & Difficulty in sleep & 1.21 & 1.06 \\
Item 4 & Disturbance in work and study & 1.58 & 1.11 \\
Item 5 & Difficulty in daily activities & 1.59 & 1.12 \\
Item 6 & Foods could not eat & 0.66 & 0.904 \\
Item 7 & Difficulty in enjoying food & 1.29 & 1.08 \\
Item 8 & Change in the sense of taste & 0.81 & 0.86 \\
Item 9 & Difficult to open mouth & 0.75 & 0.90 \\
Item 10 & Sores on tongue & 0.88 & 0.97 \\
Item II & Sores on your cheeks & 1.10 & 1.07 \\
Item 12 & Sores on lips & 0.95 & 0.98 \\
Item 13 & Bad taste or bad smell in mouth & 0.91 & 0.93 \\
Item 14 & Food debris under the appliance & 1.41 & 1.14 \\
\hline
\end{tabular}

Notes: No instances $=0$, few instances $=1$, some instances $=2$, several instances $=3$, numerous instances $=4$. positive correlation with oral health impact score Furthermore, income level was found to affect the oral health quality of life of orthodontic patients. Hence, our study hypothesis is accepted that there is a difference between removable and fixed appliance patients in terms of daily activity limits, food consumption, and oral symptoms.

In this study, fixed orthodontic patients reported greater sleep difficulty than removable patients after appliance activation. It could be related to the higher problems of adaptation faced during newly placed therapeutic components of fixed orthodontics compared to the removable appliances in the oral cavity. Moreover, increased anxiety towards fixed appliance therapy could have affected the sleep quality of the patients. Our finding is similar to the previously reported studies in which sleeping difficulty was reported among patients undergoing fixed orthodontic therapy. ${ }^{12,15,25}$ On the contrary, Alajmi et al found no significant differences in sleep difficulties between patients undergoing fixed and Invisalign orthodontic treatment. ${ }^{19}$ While $\mathrm{Wu}$ et al did not find any difference in sleeping problems between lingual and buccal fixed orthodontic patients. ${ }^{26}$

In our study, fixed orthodontic patients had a higher incidence of mucosal sores on the lips, tongue, and cheeks due to the use of metal brackets, wires, and bands, which increases the risk of mucosal irritation than the removable appliance therapy. This finding is in line with the previously reported studies on fixed orthodontic appliances. ${ }^{15,19}$ 
Table 3 Comparison of Individual Impact Scores Between Fixed and Removable Appliances Patients

\begin{tabular}{|c|c|c|c|c|c|c|}
\hline \multirow[t]{2}{*}{ Domains } & \multirow[t]{2}{*}{ Items } & \multicolumn{2}{|c|}{ Fixed } & \multicolumn{2}{|c|}{ Removable } & \multirow[t]{2}{*}{$\mathbf{p}^{\S}$} \\
\hline & & Mean & SD & Mean & SD & \\
\hline \multirow[t]{5}{*}{ Limitation of daily activities } & Difficulty in speaking & 1.25 & 1.00 & 1.28 & 1.08 & 0.971 \\
\hline & Difficulty in swallowing & 0.88 & 0.93 & 1.09 & 1.03 & 0.295 \\
\hline & Difficulty in sleep & 1.28 & 1.10 & 0.94 & 0.88 & $0.024^{*}$ \\
\hline & Disturbance in work and study & 1.61 & I.II & $\mathrm{I} .47$ & I.II & 0.640 \\
\hline & Difficulty in daily activities & 1.67 & 1.12 & 1.31 & 1.12 & 0.531 \\
\hline \multirow[t]{3}{*}{ Limitations and disturbance in eating } & Foods could not eat & 0.72 & 0.951 & 0.438 & 0.67 & 0.540 \\
\hline & Difficulty in enjoying food & 1.39 & 1.06 & 0.94 & I.II & 0.093 \\
\hline & Change in the sense of taste & 0.83 & 0.87 & 0.75 & 0.84 & 0.177 \\
\hline \multirow[t]{6}{*}{ Oral symptoms } & Difficult to open mouth & 0.79 & 0.94 & 0.63 & 0.75 & 0.157 \\
\hline & Sores on tongue & 0.97 & 1.00 & 0.56 & 0.76 & $0.042^{*}$ \\
\hline & Sores on your cheeks & 1.20 & 1.11 & 0.72 & 0.81 & $0.027 *$ \\
\hline & Sores on lips & 1.03 & 1.02 & 0.69 & 0.78 & 0.111 \\
\hline & Bad taste or bad smell in mouth & 0.99 & 0.98 & 0.63 & 0.61 & 0.085 \\
\hline & Food debris under the appliance & 1.53 & 1.16 & 1.00 & 0.95 & $0.021^{*}$ \\
\hline
\end{tabular}

Notes: ${ }^{*}<<0.05$, ${ }^{\S}$ Mann-Whitney test.

Abbreviation: SD, standard deviation.

Table 4 Comparison of Oral Health Impact Scores Across Different Demographic and Treatment Variables

\begin{tabular}{|c|c|c|c|c|c|c|}
\hline \multicolumn{2}{|l|}{ Variables } & $\mathbf{N}$ & Mean & SD & Mean Rank & $\mathbf{p}$ \\
\hline \multirow[t]{2}{*}{ Gender } & Female & 128 & 9.09 & 4.44 & 75.98 & \multirow[t]{2}{*}{0.740} \\
\hline & Male & 22 & 8.91 & 4.05 & 72.68 & \\
\hline \multirow[t]{2}{*}{ Education } & Intermediate/High school & 22 & 9.95 & 4.01 & 83.91 & \multirow[t]{2}{*}{0.322} \\
\hline & College & 128 & 8.91 & 4.43 & 74.05 & \\
\hline \multirow[t]{3}{*}{ Family income (Saudi Arabian Riyals) } & $<5000$ & 24 & 7.42 & 3.91 & $57.35 b$ & \multirow[t]{3}{*}{$0.049 *$} \\
\hline & $5000-10,000$ & 62 & 9.90 & 3.83 & $82.75 a$ & \\
\hline & $>10,000$ & 64 & 8.88 & 4.86 & $75.28 \mathrm{a}$ & \\
\hline \multirow[t]{2}{*}{ Type of orthodontic treatment } & Fixed & 118 & 9.32 & 4.31 & 78.08 & \multirow[t]{2}{*}{0.159} \\
\hline & Removable & 32 & 8.13 & 4.52 & 65.97 & \\
\hline \multirow[t]{2}{*}{ Type of practice } & Private & 117 & 8.82 & 4.43 & 73.08 & \multirow[t]{2}{*}{0.195} \\
\hline & Government & 33 & 9.94 & 4.08 & 84.09 & \\
\hline
\end{tabular}

Notes: ${ }^{*} p<0.05$, The superscripts a, $b$ are used to indicate pairwise comparisons. Different superscript letters in a column are significantly different. Oral health impact score (Mean \pm SD) (range: 0-14).

Another interesting finding of our study is that the orthodontic patients receiving removable appliance therapy had significantly lower food impaction than fixed appliances therapy. This result is not surprising since the removable appliance is kept outside the mouth during the food intake avoiding food impaction underneath the 
Table 5 Spearman Correlation Tests

\begin{tabular}{|c|c|c|c|c|c|}
\hline \multicolumn{2}{|l|}{ Variables } & \multirow{2}{*}{$\begin{array}{c}\text { Oral Health Impact Score } \\
1.000\end{array}$} & \multirow[t]{2}{*}{ Age } & \multirow[t]{2}{*}{ Duration } & \multirow[t]{2}{*}{ Pain Intensity } \\
\hline Oral health impact score & $\mathrm{CC}$ & & & & \\
\hline & $\mathrm{P}$ & & & & \\
\hline \multirow[t]{2}{*}{ Age } & $\mathrm{CC}$ & -0.094 & 1.000 & & \\
\hline & $\mathrm{P}$ & 0.253 & & & \\
\hline \multirow[t]{2}{*}{ Duration } & $\mathrm{CC}$ & $0.339 * *$ & -0.0103 & 1.000 & \\
\hline & $\mathrm{P}$ & $<0.001$ & 0.210 & & \\
\hline \multirow[t]{2}{*}{ Pain intensity } & $\mathrm{CC}$ & $0.309 * *$ & $-0.196^{*}$ & $0.296 * *$ & 1.000 \\
\hline & $P$ & $<0.001$ & 0.017 & $<0.001$ & \\
\hline
\end{tabular}

Notes: **Correlation is significant at the 0.01 level (2-tailed), *Correlation is significant at the 0.05 level (2-tailed).

Abbreviation: CC, correlation coefficient.

removable appliance. However, some discomfort when eating may be attributed to tooth sensitivity during orthodontic movement. This finding is in line with other reported studies. ${ }^{15}$ Additionally, no significant differences were reported by study participants regarding the bad taste or bad smell.

Past study has reported that orthodontic treatment is associated with family income. ${ }^{27}$ In this study, the family income levels of the study participants were highly uneven between the two groups due to the higher treatment cost with removable orthodontic appliances. Patients with higher incomes ( $>10,000$ SAR per month) opted for removable orthodontic therapy because of the aesthetics and comfort, while those with lesser incomes preferred fixed orthodontic treatment. This result is consistent with the findings of past studies. ${ }^{14,22}$ Additionally, it has been reported that income influences pain perception, anxiety, and quality of life in people with varying socioeconomic levels due to differences in healthcare resources and environmental stresses. ${ }^{28}$ However, in our study, orthodontic patients with a family income of $<5000$ SAR have shown a significantly lower oral health impact than the other income categories indicating socioeconomic disparities related to orthodontic treatment and associated quality of life. Hence family income can act as one of the confounding factors in this study. Moreover, it is unknown to what degree income influences patients getting the orthodontic treatment that future studies need to investigate.

Patients undergoing removable and fixed orthodontic treatment reported different pain intensities. The fixed orthodontic patients reported significantly higher pain intensity than removable orthodontic patients. It was observed that the level of pain and suffering was more remarkable for the first three days in fixed orthodontic patients, and the pain rating peaked on the second day. ${ }^{29}$ It could be why fixed orthodontic patients consume more analgesics than removable orthodontic patients. This finding contradicts the study reported by Alajmi et al in which both the treatment modalities had similar pain intensities. ${ }^{19}$ In contrast, Wiedel and Bondemark found low to moderate levels of pain and discomfort in both groups. ${ }^{29}$

The oral health impact score showed a significant positive correlation with the length of orthodontic treatment and pain intensity, suggesting longer the length of orthodontic treatment, the greater the impact on oral health. Similarly, pain severity may be linked to a poor oral health-related quality of life among orthodontic patients.

One of the most important adverse effects of orthodontic treatment is speech problems. ${ }^{30}$ In our study, fixed orthodontic patients reported insignificant higher speech problems than removable orthodontic patients. Since the orthodontic appliance commonly fits on the palate or the surface of the teeth, altering tongue movement and oral cavity space, resulting in the distortion of specific sounds. ${ }^{31}$ Fixed appliances demonstrated to have a significant effect on speech output. The sounds of /i/, /s/, /t/, and $/ \mathrm{d} /$ are the most severely affected. ${ }^{32}$

In this study, both removable and fixed orthodontic patients reported nearly similar disturbances in eating and chewing foods without any significant difference. It could be due to the acquaintance of the patients to respective treatment modalities as both groups had almost similar 
duration of orthodontic treatment. However, studies have pointed out that the removable orthodontic patients had more comfortable eating and chewing than fixed appliances. This is because removable orthodontic patients could temporarily remove their appliances during meals. ${ }^{19}$ It has been reported that nearly half of the patients with removable orthodontic treatment were completely satisfied with eating and chewing compared to one-quarter of the fixed orthodontic patients. ${ }^{33}$

The removable orthodontic appliance facilitates brushing and flossing, contributing to improved oral hygiene and oral health among orthodontic patients. ${ }^{34}$ However, reported data on removable and fixed orthodontic treatment modalities of oral hygiene maintenance are indecisive since plaque and gingival scores between the two treatment options are comparable. The plaque accumulation in fixed orthodontic treatment is evident around the brackets. ${ }^{34,35}$

In this study, the removable orthodontic patients demonstrated an insignificant lower oral health impact score than the fixed orthodontic patients suggesting better OHRQoL. It could be related to the less frequent functional limitation, physical pain, physical disability, and psychological discomfort. $^{22}$

\section{Limitations of the Study}

Considerable differences in the number of participants between fixed and removable orthodontic treatment groups and an imbalanced number of males and females could have influenced the study results. Additionally, this study's concept and execution have some drawbacks. First, it was a cross-sectional study where study participants were not matched for ages, gender, and levels of malocclusion severity, treatment phase, and type of teeth movement. Second, the inclusion criteria were not extremely stringent because of patients' limited availability and willingness to participate. Third, the recall bias might have influenced the results of the study since participants were called after one of appliance activation. Finally, the nature of the pain experienced by removable and fixed orthodontic patients was not recorded. Hence the data must be carefully interpreted for generalization. A follow-up randomized controlled trial with large sample size is recommended to provide more precise results.

\section{Conclusion}

The fixed orthodontic treatment resulted in more severe pain, sleeping difficulty, sores on the tongue and cheeks, and food impaction than removable orthodontic therapy after appliance activation. However, the oral health impact score did not differ markedly between fixed and removable orthodontic patients. In addition, the length of the orthodontic treatment and pain intensity showed a significant relationship with oral health impact score.

\section{Disclosure}

The authors report no conflicts of interest for this work.

\section{References}

1. Feu D, de Oliveira BH, de Oliveira Almeida MA, Kiyak HA, Miguel JAM. Oral health-related quality of life and orthodontic treatment seeking. Am J Orthod Dentofacial Orthop. 2010;138(2):152-159. doi:10.1016/j.ajodo.2008.09.033

2. Anthony SN, Zimba K, Subramanian B. Impact of malocclusions on the oral health-related quality of life of early adolescents in Ndola, Zambia. Int J Dent. 2018;2018:7920973. doi:10.1155/2018/7920973

3. Naseri N, Baherimoghadam T, Kavianirad F, Haem M, Nikmehr S. Associations between malocclusion and self-esteem among Persian adolescent population. J Orthod Sci. 2020;9:6. doi:10.4103/jos. JOS_23_19

4. Hassan $\bar{A}$ H, Amin HES. Association of orthodontic treatment needs and oral health-related quality of life in young adults. Am J Orthod Dentofacial Orthop. 2010;137(1):42-47. doi:10.1016/j.ajodo.20 08.02.024

5. Yassir YA, McIntyre GT, Bearn DR. The impact of labial fixed appliance orthodontic treatment on patient expectation, experience, and satisfaction: an overview of systematic reviews. Eur J Orthod. 2020;42(3):223-230. doi:10.1093/ejo/cjz043

6. Alhummayani FM, Taibah SM. Orthodontic treatment needs in Saudi young adults and manpower requirements. Saudi Med J. 2018;39 (8):822-828. doi:10.15537/smj.2018.8.22337

7. al-Emran S, Wisth PJ, Böe OE. Prevalence of malocclusion and need for orthodontic treatment in Saudi Arabia. Community Dent Oral Epidemiol. 1990;18(5):253-255. doi:10.1111/j.1600-0528.1990. tb00070.x

8. Haralur SB, Addas MK, Othman HI, Shah FK, El-Malki AI, AlQahtani MA. Prevalence of malocclusion, its association with occlusal interferences and temporomandibular disorders among the Saudi sub-population. Oral Health Dent Manag. 2014;13(2):164-169.

9. Alharbi F. The prevalence of malocclusion traits in Saudi Arabia 2015-2019: an epidemiological cross sectional study. J Int Oral Health. 2020;12:129-134. doi:10.4103/jioh.jioh_200_19

10. Doll GM, Zentner A, Klages U, Sergl HG. Relationship between patient discomfort, appliance acceptance and compliance in orthodontic therapy. J Orofac Orthop. 2000;61(6):398-413. doi:10.1007/ p100001908

11. Mansor N, Saub R, Othman SA. Changes in the oral health-related quality of life $24 \mathrm{~h}$ following insertion of fixed orthodontic appliances. J Orthod Sci. 2012;1(4):98-102. doi:10.4103/22780203.105880

12. Jawaid M, Qadeer TA. Assessment of the changes in the oral health related quality of life 24 hours following insertion of fixed orthodontic appliance components - An observational cross-sectional study conducted at Bahria University Medical and Dental College Karachi. J Pak Med Assoc. 2019;69(5):677-683.

13. Schaefer I, Braumann B. Halitosis, oral health and quality of life during treatment with Invisalign $\left({ }^{\circledR}\right)$ and the effect of a low-dose chlorhexidine solution. J Orofac Orthop. 2010;71(6):430-441. doi:10.1007/s00056-010-1040-6 
14. Miller KB, McGorray SP, Womack R, et al. A comparison of treatment impacts between Invisalign aligner and fixed appliance therapy during the first week of treatment. Am J Orthod Dentofacial Orthop. 2007;131(3):302.e1-9. doi:10.1016/j.ajodo.2006.05.031

15. Shalish M, Cooper-Kazaz R, Ivgi I, et al. Adult patients' adjustability to orthodontic appliances. Part I: a comparison between Labial, Lingual, and Invisalign ${ }^{\mathrm{TM}}$. Eur J Orthod. 2012;34(6):724-730. doi:10.1093/ejo/cjr086

16. Ilijazi Shahiqi D, Dogan S, Krasniqi D, Ilijazi D, Anic Milosevic S. Psycho-social impact of malocclusion in adolescents in Kosovo. Community Dent Health. 2021;38(2):71-75. doi:10.1922/ CDH_00106Milosevic05

17. Berhan Nordin EA, Shoaib LA, Mohd Yusof ZY, Manan NM, Othman SA. Oral health-related quality of life among 11-12 year old indigenous children in Malaysia. BMC Oral Health. 2019;19 (1):152. doi:10.1186/s12903-019-0833-2

18. Reissmann DR, John MT, Sagheri D, Sierwald I. Diagnostic accuracy of parents' ratings of their child's oral health-related quality of life. Qual Life Res. 2017;26(4):881-891. doi:10.1007/s11136-016-1427-y

19. Alajmi S, Shaban A, Al-Azemi R. Comparison of short-term oral impacts experienced by patients treated with Invisalign or conventional fixed orthodontic appliances. Med Princ Pract. 2020;29 (4):382-388. doi:10.1159/000505459

20. Zamora-Martínez N, Paredes-Gallardo V, García-Sanz V, GandíaFranco JL, Tarazona-álvarez B. Comparative Study of Oral HealthRelated Quality of Life (OHRQL) between different types of orthodontic treatment. Medicina. 2021;57(7):683. doi:10.3390/ medicina57070683

21. White DW, Julien KC, Jacob H, Campbell PM, Buschang PH. Discomfort associated with Invisalign and traditional brackets: a randomized, prospective trial. Angle Orthod. 2017;87(6):801-808. doi:10.2319/091416-687.1

22. Gao M, Yan X, Zhao R, et al. Comparison of pain perception, anxiety, and impacts on oral health-related quality of life between patients receiving clear aligners and fixed appliances during the initial stage of orthodontic treatment. Eur J Orthod. 2021;43 (3):353-359. doi:10.1093/ejo/cjaa037

23. Almasoud NN. Pain perception among patients treated with passive self-ligating fixed appliances and Invisalign ${ }^{\circledR}$ aligners during the first week of orthodontic treatment. Korean J Orthod. 2018;48(5):326332. doi:10.4041/kjod.2018.48.5.326

24. Al Nazeh AA, Alshahrani I, Badran SA, et al. Relationship between oral health impacts and personality profiles among orthodontic patients treated with Invisalign clear aligners. Sci Rep. 2020;10 (1):20459. doi:10.1038/s41598-020-77470-8
25. Kim MY, Park JH, Jung NY, et al. The influence of sleep quality of patients at initial stage of orthodontic treatment. JDHS. 2014;14 (3):343-351. doi:10.13065/jksdh.2014.14.03.343

26. Wu AKY, McGrath C, Wong RWK, Wiechmann D, Rabie ABM. A comparison of pain experienced by patients treated with labial and lingual orthodontic appliances. Eur J Orthod. 2010;32(4):403-407. doi:10.1093/ejo/cjp117

27. Germa A, Kaminski M, Nabet C. Impact of social and economic characteristics on orthodontic treatment among children and teenagers in France. Community Dent Oral Epidemiol. 2010;38(2):171179. doi:10.1111/j.1600-0528.2009.00515.x

28. Ham OK, Chee W, Im EO. The influence of social structure on cancer pain and quality of life. West J Nurs Res. 2017;39(12):1547-1566. doi:10.1177/0193945916672663

29. Wiedel AP, Bondemark L. A randomized controlled trial of selfperceived pain, discomfort, and impairment of jaw function in children undergoing orthodontic treatment with fixed or removable appliances. Angle Orthod. 2015;86(2):324-330. doi:10.2319/040215219.1

30. Papageorgiou SN, Gölz L, Jäger A, Eliades T, Bourauel C. Lingual vs. labial fixed orthodontic appliances: systematic review and metaanalysis of treatment effects. Eur J Oral Sci. 2016;124(2):105-118. doi: $10.1111 /$ eos. 12250

31. Haydar B, Karabulut G, Ozkan S, Aksoy AU, Ciğer S. Effects of retainers on the articulation of speech. Am J Orthod Dentofacial Orthop. 1996;110(5):535-540. doi:10.1016/s0889-5406(96)70062-8

32. Chen J, Wan J, You L. Speech and orthodontic appliances: a systematic literature review. Eur J Orthod. 2018;40(1):29-36. doi:10.1093/ejo/cjx023

33. Flores-Mir C, Brandelli J, Pacheco-Pereira C. Patient satisfaction and quality of life status after 2 treatment modalities: invisalign and conventional fixed appliances. Am J Orthod Dentofacial Orthop. 2018;154(5):639-644. doi:10.1016/j.ajodo.2018.01.013

34. Miethke RR, Brauner K. A Comparison of the periodontal health of patients during treatment with the Invisalign system and with fixed lingual appliances. J Orofac Orthop. 2007;68(3):223-231. doi:10.1007/s00056-007-0655-8

35. Azaripour A, Weusmann J, Mahmoodi B, et al. Braces versus Invisalign $^{\circledR}$ : gingival parameters and patients' satisfaction during treatment: a cross-sectional study. BMC Oral Health. 2015;15:69. doi:10.1186/s12903-015-0060-4
Patient Preference and Adherence

\section{Publish your work in this journal}

Patient Preference and Adherence is an international, peer-reviewed, open access journal that focusing on the growing importance of patient preference and adherence throughout the therapeutic continuum. Patient satisfaction, acceptability, quality of life, compliance, persistence and their role in developing new therapeutic modalities and compounds to optimize clinical outcomes for existing disease states are major areas of interest for the journal. This journal has been accepted for indexing on PubMed Central. The manuscript management system is completely online and includes a very quick and fair peer-review system, which is all easy to use. Visit http:// www.dovepress.com/testimonials.php to read real quotes from published authors. 